\title{
O Facebook e a comunidade de fala dos usuários da página oficial da Assembleia de Deus na Paraíba
}

\author{
The Facebook and the speech community of users of the official website of the \\ Assembly of God in Paraiba
}

Facebook y la comunidad lingüística de los usuarios de la página web oficial de la Asamblea de Dios en Paraíba

Ramon Nascimento ${ }^{I}$

Juciano Sousa Lacerda ${ }^{2}$

\section{Resumo}

Uma prática comunicativa está sendo desenvolvida no ambiente de comentários feitos por usuários da página da igreja evangélica Assembleia de Deus na Paraíba no Facebook. A página ADPB Oficial foi criada com o intuito de divulgar eventos da própria igreja, porém o uso dos que a seguem e os comentários feitos em determinadas postagens está fazendo com que uma nova comunidade de fala entre em formação, diante do contexto de que a liderança da igreja não tem o costume de realizar assembleias deliberativas com os membros, afim de atender a demanda dos mesmos. O objetivo deste artigo é analisar certas estratégias de discursos que muitas vezes quebram determinados padrões estabelecidos historicamente na denominação assembleiana. É no ambiente digital que essa comunidade ganha força e começa a interferir no funcionamento institucional de como a liderança deve agir.

Palavras-chave: Esfera Pública. Sociabilidade. Práticas sociais. ADPB.

\begin{abstract}
A communicative practice is being developed in the environment of comments made by users of the evangelical church page Assembleia de Deus na Paraíba on Facebook. The ADPB Official page was created in order to spread the church itself events, but the use of that follow and comments made in certain posts is causing a new community of talks being formed, on the context of that leadership the church does not have the habit of performing deliberative meetings with members, in order to meet the demand of them. The purpose of this article is to analyze certain strategies of discourses that often break certain patterns historically established in Assembleia's denomination. It is in the digital environment that community gains strength and begins to interfere in the institutional functioning of how leadership must take action.
\end{abstract}

Keywords: Public Sphere. Sociability. Social practices. ADPB.

\begin{tabular}{|c|c|}
\hline \multirow{3}{*}{ 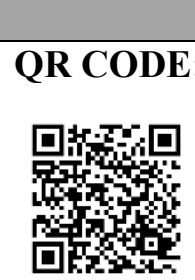 } & Acesse este artigo online \\
\hline & $\begin{array}{l}\text { Website: } \\
\text { http://www.revistas.ufg.br/index.php/ci }\end{array}$ \\
\hline & $\begin{array}{l}\text { DOI: } \\
\text { http://dx.doi.org/10.5216/36991 }\end{array}$ \\
\hline
\end{tabular}

\section{Resumen}

Una práctica comunicativa se está desarrollando en el entorno de los comentarios realizados por los usuarios de la página de la Asamblea de la iglesia evangélica de Dios en Paraíba en Facebook.

\footnotetext{
${ }^{1}$ Mestrando no Programa de Pós-graduação em Estudos da Mídia pela Universidade Federal do Rio Grande do Norte (UFRN). Natal, Rio Grande do Norte, Brasil. E-mail: ramoncomunicologo@gmail.com

2 Doutor e mestre em Ciências da Comunicação pela Universidade do Vale do Rio dos Sinos (UNISINOS). Professor Adjunto da Universidade Federal do Rio Grande do Norte (UFRN), docente do Programa de Pósgraduação em Estudos da Mídia da UFRN. Brasil, Rio Grande do Norte, Natal. E-mail: juciano.lacerda@gmail.com
} 
La página ADPB Oficial se creó con la intención de difundir la propia eventos iglesia, pero el uso de esa siguen y los comentarios hechos en los cargos está provocando una nueva comunidad de las conversaciones entre la formación, en el contexto de que el liderazgo la iglesia no tiene la costumbre de llevar a cabo reuniones de deliberación con los miembros, con el fin de satisfacer la demanda de ellos. El propósito de este artículo es analizar ciertas estrategias de los discursos que a menudo rompen ciertos patrones históricamente establecidos en la denominación assembleiana. Es en el entorno digital que la comunidad gana fuerza y comienza a interferir en el funcionamiento institucional de cómo el liderazgo debe actuar.

Palabras clave: Esfera Pública. Sociabilidad. Practicas sociales. ADPB.

\section{INTRODUÇÃO}

instituição religiosa consegue reunir um determinado número de pessoas,
formando uma comunidade maior, e cada indivíduo dessa comunidade se
identifica com os ideais propagados pelos líderes dessa massa e, a partir daí, esse indivíduo começa a ser ator de sua própria prática, seja ela religiosa, comunicacional, no âmbito das práticas sociais.

A igreja mesmo resistindo a determinados usos dos meios de comunicação, como é o caso específico do cinema no contexto da Assembleia de Deus na Paraíba, por outro lado começou a tentar dialogar com o fiel, mesmo que tardiamente, nas redes sociais. Muito mais com a característica de informar do que comunicar, a liderança da igreja foi surpreendida com a nova característica própria das redes. A comunicação autônoma dos indivíduos pegou de surpresa a própria liderança da igreja, que até hoje tenta timidamente lidar com essa nova prática comunicativa, quebrando os padrões clássicos de comunicação estabelecidos historicamente na instituição.

Neste artigo trataremos de uma prática comunicacional que foi ampliada no contexto da cibercultura. Nosso objeto de análise, mesmo sendo recortado a partir de sua ambiência digital, também está inserido no campo social da religião, que também teve de apropriar-se de espaços comunicacionais midiatizados, gerando outros fenômenos da comunicação, a partir da utilização dos meios tradicionais e digitais de comunicação.

No contexto da Assembleia de Deus na Paraíba (ADPB), sempre foi habitual um membro reclamar de um determinado líder; fazer pedidos para a construção do templo onde ele congrega; de discordar de determinada atitude da liderança. Mas em toda a história da igreja, esse "dizer do fiel" nunca se tornou público ${ }^{3}$ como tornou-se agora com o uso das redes sociais. Hoje, esse mesmo fiel faz isso a hora que quiser, basta "deslocar sua palavra" para página oficial

\footnotetext{
${ }^{3}$ Não há instâncias de deliberação coletiva na ADPB, mas somente os grupos que se formam depois do culto.
}

Comun. \& Inf., Goiânia, GO, v. 18, n. 2, p. 112-125, jul./dez. 2015 
da igreja no Facebook e os usuários que conseguem visualizar o comentário tem acesso ao que foi dito por este membro da igreja.

\section{CONHECENDO A ASSEMBLEIA DE DEUS NA PARAÍBA}

A ADPB é a maior denominação evangélica do Estado, segundo dados do $\mathrm{IBGE}^{4}$. A igreja, que hoje conta com aproximadamente 1.000 templos e 120 mil membros ${ }^{5}$ e congregados $^{6}$, ligados à sede de João Pessoa (capital), foi fundada no ano de 1918 num sítio localizado próximo à cidade de Alagoa Grande, município paraibano. Ela é fruto do chamado pentecostalismo clássico que nasceu em Belém do Pará com a vinda de dois missionários suecos, Daniel Berg e Gunnar Vingren, que chegaram ao Brasil com o objetivo de evangelização.

A ADPB, para contextualizar nosso objeto de pesquisa, precisamente nos anos de 1980, proibia seus fiéis, que aqui os chamo de membros, de assistirem TV, muito menos de possuírem um aparelho em suas casas. Hoje, essa mesma igreja possui uma rádio FM; a cada dois meses publica uma revista de 16 páginas, com distribuição gratuita para todas as igrejas da capital da Paraíba e algumas do interior; possui também um site e ainda mantém perfis cadastrados nas principais redes sociais, dentre eles, uma página no Facebook com mais de 12.200 fãs ${ }^{7}$.

A ADPB é ligada a Convenção de Ministros da Assembleia de Deus no Estado da Paraíba (COMADEP), a qual é ligada a Convenção Geral das Assembleias de Deus no Brasil (CGADB), e em cada Estado brasileiro essa instituição religiosa possui autonomia por meio de um estatuto que regula e normatiza as características singulares que cada igreja possui. E cada convenção estadual é liderada por um pastor-presidente eleito a cada dois anos, podendo ser reeleito quantas vezes concorrer ao cargo. O presidente na ADPB está no $7^{\circ}$ mandato.

Não só na $\mathrm{ADPB}$, como em todas as Assembleias de Deus no Brasil, existe uma hierarquia ministerial, que segundo a liderança da igreja atende a um contexto bíblico e estatutário. Após ser batizado nas águas a partir dos 15 anos de idade, o congregado, seja homem ou mulher, torna-se membro. $\mathrm{Na} \mathrm{ADPB}$, o homem casado, membro da igreja, pode ser auxiliar ministerial, por vontade própria e consentimento da liderança. Se esse auxiliar for

\footnotetext{
${ }^{4}$ Instituto Brasileiro de Geografia e Estatística, a partir do censo feito em 2010.

${ }^{5}$ Fiéis que foram batizados nas águas.

${ }^{6}$ Pessoa que participa dos cultos constantemente, mas ainda não é membro.

${ }^{7}$ Pessoas que curtem a página do Facebook para acompanhar as publicações que o departamento de mídia da igreja está fazendo.
}

Comun. \& Inf., Goiânia, GO, v. 18, n. 2, p. 112-125, jul./dez. 2015 


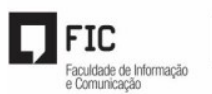

batizado no Espírito Santo ${ }^{8}$, o corpo ministerial pode o consagrar Diácono, depois Presbítero, Evangelista e Pastor. Porém também existem funções que são exclusivas das mulheres, do tipo dirigentes de círculo de oração.

É fundamental apresentar aqui as características gerais do corpo administrativo e doutrinário da ADPB para que possamos situar o contexto de fala de seus membros. Já que estamos analisando a ação comunicativa dos usuários da página ADPB Oficial no Facebook precisamos entender em que contexto está situado aquele que fala, que reclama, que debate, que sugere. Porém o pouco espaço que temos no artigo nos proporciona apresentarmos as características gerais da instituição.

Dentro de qualquer templo da Assembleia de Deus no Brasil existem áreas reservadas para públicos específicos. Até o início dos anos 1990, na ADPB, as mulheres sentavam separadas dos homens, sendo as mulheres do lado esquerdo e os homens do lado direito em referência ao púlpito9 . Mas ainda hoje existem áreas físicas não compartilhadas pelo "membro comum", como é o caso da área que fica atrás do púlpito, local onde apenas Diáconos, Presbíteros, Evangelistas e Pastores sentam durante a cerimônia religiosa da ADPB. Isso não significa dizer que o membro não tenha acesso a ele.

A Figura 1 a seguir exemplifica bem o que estamos dizendo. Uma foto tirada durante um culto no templo central da ADPB é de uma mulher que está falando no microfone, porém na retarguada dela só existem homens de paletó e gravata, que também é um dos requisitos para sentar ali durante um culto. Mulheres e crianças sobem para falar ou cantar, mas jamais sentar, durante a celebração.

Figura 1 - Púlpito do templo sede da ADPB durante uma celebração religiosa

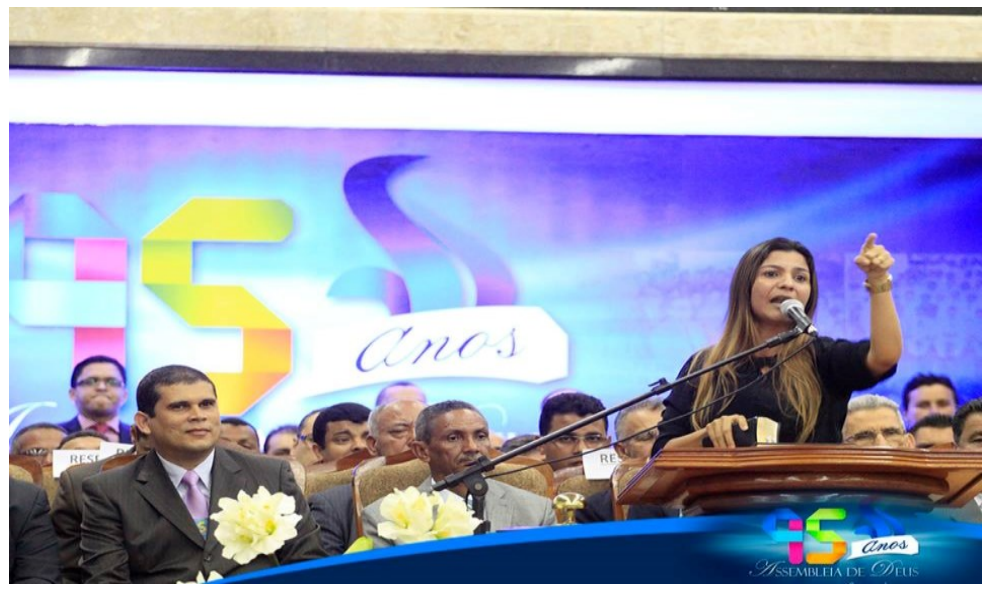

Fonte: ADPB Oficial, 2015

\footnotetext{
${ }^{8}$ Para os pentecostais assembleianos, a ênfase do batismo no Espírito Santo está no falar em línguas estranhas.

${ }^{9}$ Local onde o pastor faz uso do microfone para dirigir aos fiéis durante a celebração religiosa.
}

Comun. \& Inf., Goiânia, GO, v. 18, n. 2, p. 112-125, jul./dez. 2015 
Porém essas são apenas características de formação de microcomunidades dentro da comunidade assembleiana como um todo. Os obreiros, dos quais são chamados esses homens da figura acima, as crianças, os jovens, o coral possuem espaços físicos dentro do templo os quais a partir dali são reconhecidos. O membro que não faz parte do coral não pode sentar no espaço que é reservado para o coral se apresentar todos os domingos na igreja. Percebemos que, enquanto a igreja legitima certas comunidades para sua organização social e religiosa, no ambiente da página ADPB Oficial isso não acontece, porque todos que curtem a página o fazem por interesse em acompanhar a produção midiática da instituição no Facebook. Nas redes sociais, o pastor não é mais importante do que o membro, porém o poder simbólico que possui diante dos membros dentro da igreja, o legitima diante dos usuários da página que o conhecem mesmo antes do uso das redes sociais. O pastor é tanto líder desses membros dentro do templo quanto líder na página.

Diante da formação dessas microcomunidades que tratamos acima, as redes sociais proporcionam também esses espaços. No próprio Facebook existem grupos abertos e fechados que são criados por jovens da $\mathrm{ADPB}$, senhoras da $\mathrm{ADPB}$, pela equipe que trabalha com as crianças da igreja. Mas, no nosso caso, estamos analisando uma página em que não há restrinção nem por faixa etária, nem daqueles que não são membros da igreja. Ou seja, numa página do Facebook pressupõem que todos são iguais na intenção de interagir vinculadosa um interesse comum.

E diante das características já citadas, o fator que mais contribui para nosso interesse na pesquisa é saber que a Assembleia de Deus não realiza fóruns de discussão e nem assembleias ou algo do tipo com o "membro comum" da instituição, nem no ambiente off e nem no online. A única assembleia de caráter ordinário e extraordinário, realizada pela COMADEP, apenas os obreiros participam e ela acontece uma vez por ano. Nota-se aqui uma característica interna de esfera discursiva dominante em que a liderança convencional toma as decisões a partir de sua competência administrativa.

Em todas as Assembleias de Deus do Brasil acontecem as Escolas Bíblicas de Obreiros, um evento anual em que dentro da programação são realizadas as Assembleias Ordinárias e Extraordinárias de caráter convencional. A figura a seguir trata de uma Escola Bíblica que aconteceu em 2014 na Assembleia de Deus do Belenzinho,em São Paulo. Perceba na foto (Figura 2) que todos os homens estão de paletó e gravata e ainda observando mais, não identificamos a presença de mulheres e crianças. 


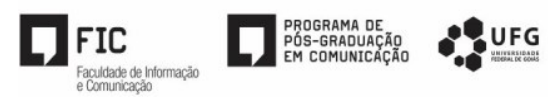

Figura 2 - Reunião de obreiros durante evento na AD em São Paulo

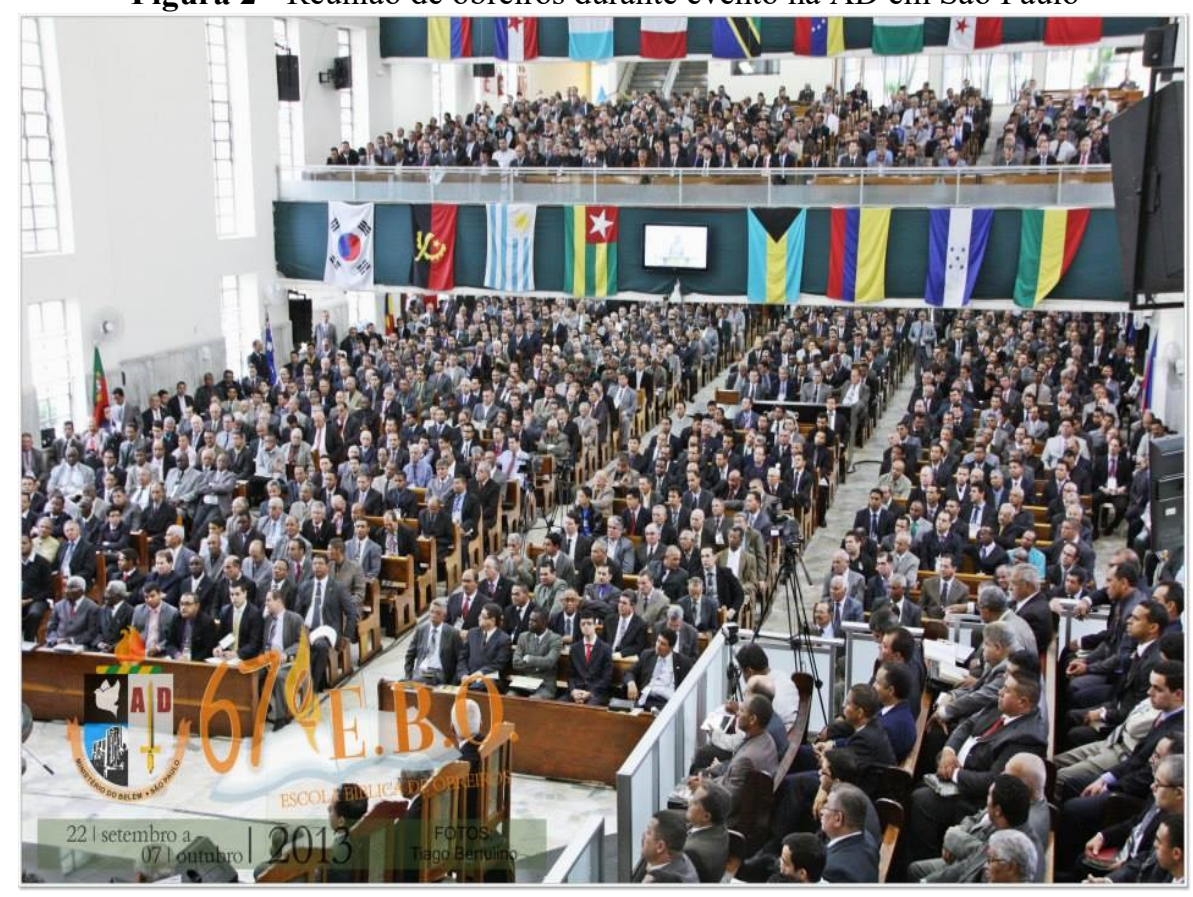

Fonte: CGADB, 2013

Antes da comunicação digital, os membros quando criticavam a instituição ou o próprio pastor da igreja, o faziam em grupos formados por afinidades que se reuniam nas calçadas do templo, nas residências de outros membros, nas reuniões de restaurantes, enfim, na esfera privada.O máximo que um pastor teria tempo e espaço para ouvir o membro seria num atendimento agendado no gabinete pastoral numa conversa particular e isso ainda acontece na ADPB. Mas a partir do uso das redes sociais, esses membros transferem seus comentários do privado para a ambiência digital, gerando visibilidade, e nos parece que uma microesfera social discursiva entra em formação, ou melhor, a prática agora é pública.

\subsection{ADPB OFICIAL}

A página da ADPB (Figura 3), no Facebook, foi criada em 20 de Janeiro de 2012 e é entitulada de ADPB Oficial. Uma página que está com 12.259 fãs ${ }^{10}$, os quais têm acesso ao conteúdo publicado pelo departamento de mídia da igreja.

Conforme nossas observações, a página é "alimentada" em média três vezes por semana, com assuntos exclusivamente institucionais, principalmente com divulgação de eventos. Os

${ }^{10} \mathrm{https}$ //www.facebook.com/pages/ADPB-Oficial/175978849173305?ref=hl Acesso em: 04 de março de 2015.

Comun. \& Inf., Goiânia, GO, v. 18, n. 2, p. 112-125, jul./dez. 2015 
पFIC

usuários que seguem a página podem ser direcionados ao site da igreja, clicando no link de notícias, além de poderem curtir, compartilhar e/ou comentar cada post.

A maior interação percebida nessa página está nos comentários de algumas postagens. Como novo espaço de discussão temática, os membros da igreja estabelecem diálogos acerca de determinados assuntos institucionais se posicionando contra ou a favor de tal tema, gerando assim um evento comunicacional, que sempre aparece pelas próprias ações estratégicas da instituição.

Figura 3 - Página da Assembleia de Deus da Paraíba no Facebook

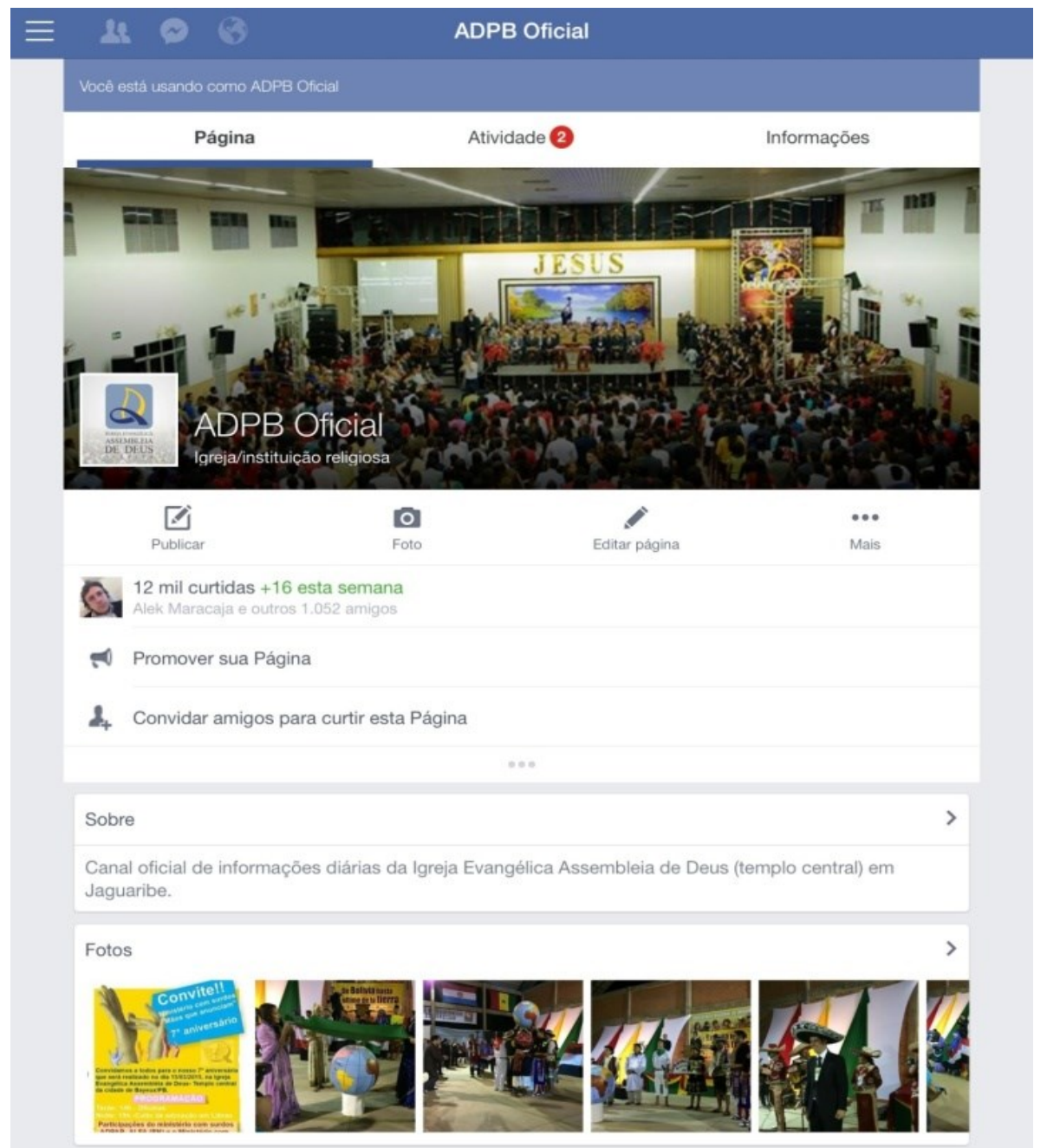

Fonte: ADPB Oficial, 2015

Nossa pesquisa dialoga com a noção de Esfera Pública enquanto esfera do agir comunicativo; da esfera do dizer e querer ser ouvido; da reivindicação gerada a partir da insatisfação e do tornar público aquilo que é dito. Mas para amarrarmos bem essa ideia, faz necessário contextualizarmos e conceitualizarmos a Esfera Pública a partir do seu expoente clássico, Jürgen Habermas.

Comun. \& Inf., Goiânia, GO, v. 18, n. 2, p. 112-125, jul./dez. 2015 


\section{ESFERA DO AGIR COMUNICATIVO}

O filósofo alemão Jürgen Habermas atentou para uma Europa que passou por duas grandes revoluções, a Industrial e a Francesa, resultanto no deslocamento do poder central de uma aristocracia para a burguesisa e na migração populacional do campo para a cidade.

No livro Mudança Estrutural da Esfera Pública, escrito em 1962, Habermas nos apresenta o primeiro conceito:

Esfera Pública pode ser entendida inicialmente como a esfera das pessoas privadas reunidas em um público; elas reivindicam esta esfera pública regulamentada pela autoridade, mas diretamente contra a própria autoridade, a fim de discutir com ela as leis gerais da troca na esfera fundamentalmente privada, mas publicamente relevante, as leis do intercâmbio de mercadorias e do trabalho social (HABERMAS, 1984, p. 42).

Na obra do autor encontramos uma Esfera Pública típica de época e jamais podemos resgatar esse conceito original e aplicarmos ao contexto atual sem que façamos análises e aplicações minuciosas e atentando para as mutações que a cibercultura provocou na contemporaneidade. Mesmo assim, Habermas é importante no entendimento de Esfera Pública por ser o precursor da teoria e por rever seu conceito original, posteriormente, entendendo a mídia como capaz de libertar os processos comunicativos, de acordo com Maia (2014).

Em nossa perspectiva de compreensão do pensamento de Habermas, propomos um exercício de articular seu pensamento com autores que tanto dialogam como criticam o filósofo, dos quais Bernard Miège (2014), Wilson Gomes e Rosiley Maia (2008), Luís Mauro Sá Martino (2014) e Heloísa Matos (2014), os quais facilitam a compreensão e aplicação do conceito original de Esfera Pública.

Habermas põe o Agir Comunicativo, sua teoria clássica, como característica principal no processo de formação da Esfera Pública, sendo um espaço de discussão. E essa ação limitava-se à nova classe burguesa, em ascensão na época, que exercendo a liberdade de expressão em espaços públicos e legitimados contribuía para a consolidação da democracia em território europeu no século XVIII.

Ele reconheceu a Esfera Pública hegemônica condicional, pois sua origem foi identificada na indústria jornalística européia. E depois, o próprio Habermas reconhece que essa Esfera hegemônica caminha para algum lugar. Uma anotação feita por Miège (2014) refere-se a não ser mais aceitável pensar num espaço público homogêneo e único na atualidade.

Na Europa dos séculos XVIII e XIX, o desenvolvimento da imprensa gerou o contexto ideal de aproximação entre os jornais e os leitores. Foi essa proximidade que permitiu aos burgueses praticar o "uso público da razão para a argumentação e a troca de opiniões, e assim

Comun. \& Inf., Goiânia, GO, v. 18, n. 2, p. 112-125, jul./dez. 2015 
criar um espaço de mediação entre o Estado (habituado ao segredo durante a monarquia) e o espaço das vidas privadas" (MIÈGE, 1999, p. 4).

A crítica que se faz a Habermas, quando ele escreve sua primeira obra sobre Esfera Pública, é de que ele não considerou o potencial midiático, prevendo que a mídia poderia destruir a Esfera Pública oriunda das conversações e debates. "Habermas revê sua posição e aponta que os meios de comunicação permitem que esferas públicas apareçam através de uma rede virtualmente presente de conteúdos da comunicação que pode se mover no espaço e tempo" (MATOS, 2014, p. 156).

Hoje a Esfera Pública não está limitada a um lugar específico, ela é um lugar abstrato de interação. Ela não é um local físico de reunião daqueles que se comunicam, mas é a reunião daqueles que se comunicam num determinado local, seja ele numa ambiência física ou digital.

\subsection{A NOÇÃO DE ESFERA PÚBLICA NA PÁGINA ADPB OFICIAL}

Sabendo que no ciberespaço a esfera da ação comunicativa é ampliada, concluímos que, graças à Internet as pessoas, as empresas, as instituições, os partidos, os agrupamentos e qualquer comunidade, como é o caso dos usuários que comentam na página ADPB Oficial, tornaram-se atores do seu próprio “dizer" e, corroborando com Lemos (2010), são eles quem decidem sobre aquilo que vão publicar na web.

Compreendemos então que as pessoas sempre têm muitas coisas a dizer, imagens e músicas a difundir, coisas a trocar, injustiças a denunciar, sofrimentos a expressar, histórias a contar, opiniões a oferecer, questões a colocar, poemas a declarar, testemunhos a compartilhar, fotos a mostrar, músicas a serem ouvidas. E esse descolamento da palavra, esse "poder de dizer enfim", esse "mostrar" e "se mostrar" generalizado é que é uma das principais dimensões da revolução ciberdemocrática em curso (LEMOS; LÉVY, 2010, p. 89-90).

No entanto, é necessário reforçarmos a cautela que temos ao afirmar que todos os espaços, diálogos e comentários publicados na Internet, e em nosso caso na página ADPB Oficial, é um espaço que se configura como Esfera Pública. Porque para Martino (2014) nem todo debate faz parte da Esfera Pública conectada:

A princípio podemos pensar na internet como uma elaboração contemporânea da Esfera Pública entendida como o espaço democrático de troca de ideias entre os cidadãos. [...]. No entanto, para além dessas aparentes possibilidades, as interações políticas na internet nem sempre se caracterizam pela democracia; discussões sobre temas de interesse público muitas vezes perdem seu foco, tornando-se espaços de disputas e intrigas pessoais (MARTINO, 2014, p. 90).

Comun. \& Inf., Goiânia, GO, v. 18, n. 2, p. 112-125, jul./dez. 2015 
Na comunidade de fala a qual estamos pesquisando, não é natural um usuário denegrir a imagem de outros usuários da página e nem muito menos a figura do líder da igreja. A maioria dos textos escritos pelos usuários se dá em torno do interesse coletivo em assuntos que dizem respeito àinstituição, como observamos na figura a seguir sobre a divulgação do projeto de reforma do templo central da ADPB (Fifura 4).

Figura 4 - Usuários emitem opiniões à respeito do projeto de reforma na fachada do templo central da ADPB

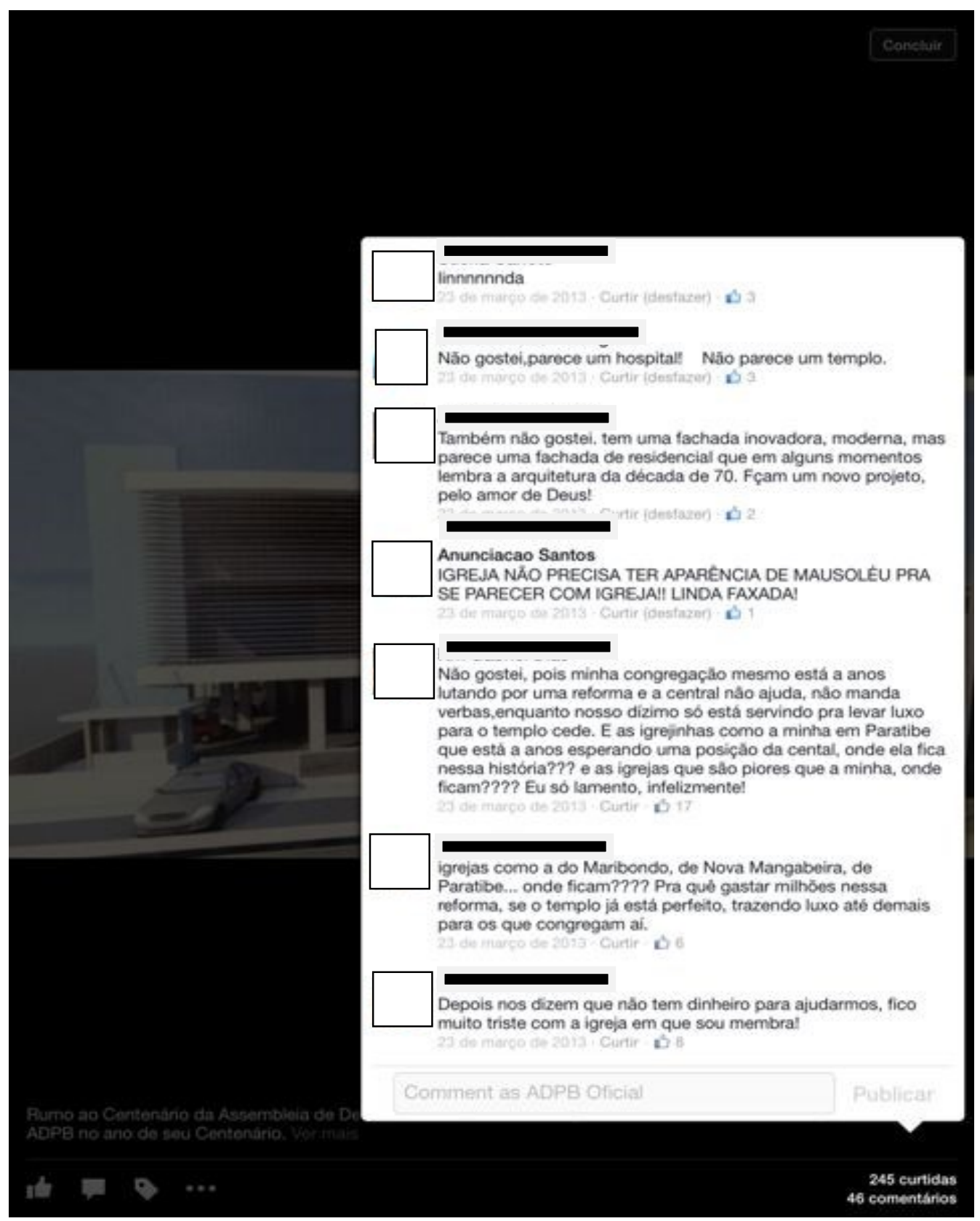

Fonte: ADPB Oficial, 2015 
Destacamos e trouxemos para análise um dos comentários acima feito pelo usuário 1 que discorda das prioridades que os líderes da igreja dão ao templo central, as quais resultam na negligência das congregações, ou seja, templos menores (Figura 5).

Figura 5 - Usuário reivindica atenção da liderança para os problemas de sua igreja.
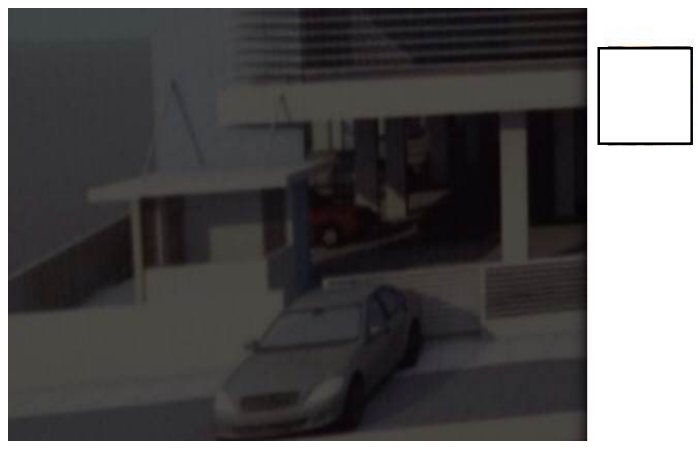

Não gostei, pois minha congregação mesmo está a anos lutando por uma reforma e a central não ajuda, não manda verbas,enquanto nosso dízimo só está servindo pra levar luxo para o templo cede. E as igrejinhas como a minha em Paratibe que está a anos esperando uma posição da cental, onde ela fica nessa história??? e as igrejas que são piores que a minha, onde ficam???? Eu só lamento, infelizmente!

23 de março de 2013 · Curtir : Bb 17

Fonte: ADPB Oficial, 2015

Numa conversa informal que tivemos com um dos pastores da igreja, ele nos disse que determinadas decisões administrativas são pensadas a partir dos comentários dos internautas. "Uma reforma num templo pode muito bem ser identificada através de uma denúncia feita pelos internautas na página da igreja", palavras de Eduardo Leandro Alves, secretário executivo de Missões da ADPB. Tal perspectiva nos leva a problematizar o circuito da interação produzido nessas relações entre fiéis e institucionalidade da Igreja, uma vez que há empiricamente evidências de que os sujeitos da interação em seus lugares de interlocução refazem ou repensam suas práticas e estratégias em função dessa mesma interação.

\section{CONSIDERAÇÕES FINAIS}

No processo de desenvolvimento de nossa investigação decidimos por selecionar os comentários que giram em torno de um tema institucional e analisando através do método de Etnografia da Fala aplicado por Máximo (2002), para identificarmos as estratégias comunicacionais dos usuários diante do contexto histórico assembleiano.

O ambiente de sociabilidade digital aponta para a configuração de novos lugares de fala reconhecidos entre membros da igreja, ainda de modo tácito, mas que começam a ganhar visibilidade diante da classe que sempre tomou as decisões da instituição centenária. "A sociabilidade é uma interação entre iguais, ou melhor, entre sujeitos que 'fazem-de-conta' que 
são iguais. Na verdade não são iguais, mas o desejo de interagir, simplesmente, coloca-os em posição de igualdade" (SIMMEL, 1983 apud MÁXIMO, 2002, p. 164).

A aplicação da Etnografia da Fala em nosso caso é apropriada porque estamos analisando os comentários feitos pelos usuários que seguem a página como eventos comunicativos, governados por um sistema de linguagem próprio da comunidade de fala assembleiana, unificando-os em suas práticas sociais e comunicacionais.

A Etnografia da Fala, mais comumente chamada de Etnografia da Comunicação, impulsionada por Dell Hymes na década de 60 e por ele definida da seguinte forma: 'A etnografia da fala está preocupada com as situações, os padrões e funções da fala enquanto uma atividade no seu próprio registro'. (Hymes, 1962, p. 101). Ou seja, tal abordagem está preocupada em investigar os padrões comunicativos e as maneiras de falar de um determinado grupo e compreender como estes se inter-relacionam com outros aspectos da cultura. Parte-se do princípio de que qualquer padrão comunicativo estará sempre relacionado com o contexto no qual foi produzido (SAVILLETROIKE, 1982 apud MÁXIMO, 2002, p. 75)

Temos ciência de que determinadas práticas dos usuários que seguem determinadas páginas ou perfis no Facebook possuem características semelhantes, diante de certa ordem da interação, pois todo mundo que usa a rede comenta, curti, compartilha, enfim. Mas analisar os eventos comunicativos dos usuários da ADPB Oficial é está atento a especificidades da prática comunicacional que a própria liderança da igreja pode não está percebendo, porque os líderes da igreja ainda não o reconhecem como um espaço deliberativo.

Também há limites a considerar no uso dessa nova ambiência digital. Apenas uma pequena parte dos membros da igreja está seguindo a página ADPB Oficial. Neste caso, os que seguem, representam $10 \%$ da quantidade de fiéis que a instituição possui. Também é preciso levar em consideração os internautas que seguem a página, mas não são membros da instituição. Outro fator a ponderar é que a página não alcança todos os usuários, pois para que eles vejam uma publicação é preciso impulsionar e pagar ao Facebook.

Outro aspecto a considerar e problematizar são os silêncios, pois nem todos que seguem a página comentam as postagens. Isso não quer dizer que devemos ignorá-los, pois podem se posicionar a qualquer momento. Mas também é preciso buscar compreender como atua o silêncio nesse ambiente de interação. Os usuários que comentam possuem uma linguagem própria, compartilhando de códigos específicos de fala, como citações bíblicas e metáforas do discurso religioso, as quais são estratégias da ação comunicativa de modo a pensar 
que agredir o outro com palavras pode, além de ferir os princípios do grupo cristão, também levá-lo a ser repreendido pelos demais que estão no mesmo ambiente que ele. Portanto, temos instigantes aspectos a problematizar nessa investigação, o que ratifica a complexidade dos processos comunicacionais midiatizados, pois acionam diversos vetores e fatores, ambientes, modos e lógicas de interação.

\section{REFERÊNCIAS}

ADPB Oficial. Página da ADPB no Facebook. Disponível em: $<$ https://www.facebook.com/pages/ADPB-Oficial/175978849173305>. Acesso em: 4 mar. 2015.

ADPB Oficial. Púlpito do templo sede da ADPB durante uma celebração religiosa. Disponível em: $<$ https://www.facebook.com/175978849173305/photos/a.449571001814087.1073741831.1759788491 73305/449572215147299/?type=3\&theater $>$. Acesso em: 4 mar. 2015.

ADPB Oficial. Usuário reivindica atenção da liderança para os problemas de sua igreja. Disponível em: $<$ https://www.facebook.com/photo.php?fbid=358099900961198\&set=a.204225706348619.36272. 175978849173305\&type=3\&theater $>$. Acesso em: 4 mar. 2015.

ADPB Oficial. Usuários emitem opiniões à respeito do projeto de reforma na fachada do templo central da ADPB. Disponível em:

$<$ https://www.facebook.com/175978849173305/photos/a.204225706348619.36272.175978849173305 /237529846351538/?type=3\&theater $>$. Acesso em: 4 mar. 2015.

GOMES, W.; MAIA, R. Comunicação e democracia. São Paulo: Paulus, 2008.

HABERMAS, J. Mudança estrutural da esfera pública. Rio de Janeiro: Tempo Brasileiro, 1984.

LEMOS, A.; LÉVY, P. O futuro da internet: em direção a uma ciberdemocracia planetária. São Paulo: Paulus, 2010.

MAIA, R. C. M. Representação política de atores cívicos e Esfera Pública. In: SOUSA, M. W.; CORRÊA, E. S. Mutações no espaço público contemporâneo. São Paulo: Paulus, 2014. p. 77-104.

MARTINO, L. M. S. Teoria das Mídias Digitais: linguagens, ambientes, redes. Petrópolis: Vozes, 2014.

MATOS, H. O processo discursivo de formação da opinião pública. In: SOUSA, M. W.; CORRÊA, E. S. Mutações no espaço público contemporâneo. São Paulo: Paulus, 2014. p. 137-162.

MÁXIMO, M. E. Compartilhando regras de fala: interação e sociabilidade na lista eletrônica de discussão Cibercultura. 2002. f. 198. Dissertação (Mestrado em Antropologia Social)Universidade Federal de Santa Catarina, Florianopólis, 2002.

MIÈGE, B. O espaço público: perpetuado, ampliado e fragmentado. São Paulo: Novos Olhares, 1999.

MIÈGE, B. Sete considerações fundamentais sobre o espaço público contemporâneo. In: SOUSA, M. W.; CORRÊA, E. S. Mutações no espaço público contemporâneo. São Paulo: Paulus, 2014. p. 2138.

Comun. \& Inf., Goiânia, GO, v. 18, n. 2, p. 112-125, jul./dez. 2015 
Recebido em: 31/07/2015

Aceito em: 16/10/2015

Publicado em: 04/12/2015

Comun. \& Inf., Goiânia, GO, v. 18, n. 2, p. 112-125, jul./dez. 2015 